\title{
NOTES
}

\section{Production, Isolation and Biological Properties of TMC-120A, $B$ and $C$, Novel Inhibitors of Eosinophil Survival from Aspergillus ustus TC 1118}

\author{
Jun KoHno*, MasaAKi SaKURAI, Noriaki Kameda, \\ MaKi Nishio, Kimio KaWano, Noboru Kishi, \\ TORU OKUDA and SABURO KOMATSUBARA \\ Discovery Research Laboratory, Tanabe Seiyaku Co., Ltd., \\ 2-2-50, Kawagishi, Toda-shi, Saitama 335-8505, Japan \\ (Received for publication April 30, 1999)
}

Eosinophils are believed to contribute proinflammatory effects in allergic inflammation, including asthma. ${ }^{1)}$ The cytokines such as hematopoietins, interleukin-5 (IL-5), IL-3 and GM-CSF have been shown to stimulate production of eosinophils in the bone marrow, ${ }^{2)}$ and the same cytokines inhibit eosinophilic apoptosis and prolong survival when eosinophils are cultured. ${ }^{3 \sim 5)}$ In allergic individuals, large numbers of eosinophils are accumulated and release activated oxygen and toxic granule-derived proteins such as major basic protein and eosinophil cationic protein. ${ }^{1)}$ Consequently, agents that inhibit the prolongation of eosinophil survival will be another candidate for development of drugs to treat bronchial asthma.

In the course of our screening for inhibitors of IL-5 mediated prolongation of eosinophil survival, a fungus, Aspergillus ustus (Bain.) Thom \& Church TC 1118 was found to produce three novel isoquinoline alkaloids, designated as TMC-120A (1), B (2) and C (3). We report here the production, isolation and biological activities of TMC-120A, B and C, and their derivatives.

A loopful of spores of the producing strain, Aspergillus ustus was inoculated into 500-ml Erlenmeyer flasks containing $70 \mathrm{ml}$ of a seed medium and incubated on a rotary shaker at $220 \mathrm{rpm}$ at $27^{\circ} \mathrm{C}$ for 5 days. The resultant seed culture $(300 \mathrm{ml})$ was transferred into a 50 -liter jar fermentor containing 30 liters of a production medium having the same composition as the seed medium. The fermentation was carried out at $27^{\circ} \mathrm{C}$ for 3 days with agitation of $200 \sim 600 \mathrm{rpm}$ and aeration of 15 liters/minute to keep the dissolved oxygen concentration at $10 \%$ of saturation.

Fig. 1. Structures of TMC-120A (1), B (2), C (3) and derivatives $(4,5)$.<smiles>C=C(C)C1Oc2c(ccc3cc(C)ncc23)C1=O</smiles>

1<smiles>CC(C)=C1Oc2c(ccc3cc(C)ncc23)C1=O</smiles>

2<smiles>Cc1cc2ccc3c(c2cn1)OC(O)(C(C)C)C3=O</smiles>

3<smiles>Cc1cc2ccc3c(c2cn1)O[C@H](C(C)C)[C@@H]3O</smiles> 
The typical time course of TMC-120s production in a 30 -liter jar is shown in Fig. 2. The $\mathrm{pH}$ and packed volume (PCV) gradually increased from the initiation of the fermentation to 120 hours. The glucose concentration was gradually decreased, and reached $0.4 \mathrm{mg} / \mathrm{ml}$ at 120 hours. Compound 2 was produced in the earth stage of the fermentation, followed by the production of 1 and 3 . The maximum production of $\mathbf{2}, \mathbf{1}$, and $\mathbf{3}$ was observed at 48,72 , and 120 hours, respectively, suggesting that 1 and 3 were derived from 2 by biological or chemical transformation. The total production of 1,2 and 3 reached the maximum at 72 hours.

The isolation procedure for TMC-120s is summarized in Fig. 3. The fermentation broth of Aspergillus ustus was extracted with 1-butanol, and the extract was purified by solvent partition and repeated column chromatography. Finally, compounds $\mathbf{2}$ and $\mathbf{3}$ were recrystallized with organic solvents to afford needles. The structure determination has been reported in a separate paper. ${ }^{6}$ )

In order to obtain a preliminary information on structureactivity relationships, 2 was reduced with sodium borohydride, giving two diastereomers, 4 ( $E$ isomer) and 5 ( $Z$ isomer). Structures of $\mathbf{4}$ and 5 were determined by comparison of ${ }^{1} \mathrm{H}$ and ${ }^{13} \mathrm{C}$ NMR data with those of $\mathbf{1}$, together with the NOESY experiments of $\mathbf{4}$ and $\mathbf{5}$ as shown in Fig. 4.
Fig. 2. Time course of TMC-120s production.

$\Delta \mathrm{pH}, \diamond$ Glucose, $+\mathrm{PCV}, \bullet \mathrm{TMC}-120 \mathrm{~A}$,

- TMC-120B, 口 TMC-120C, $\circ$ Total TMC-120s
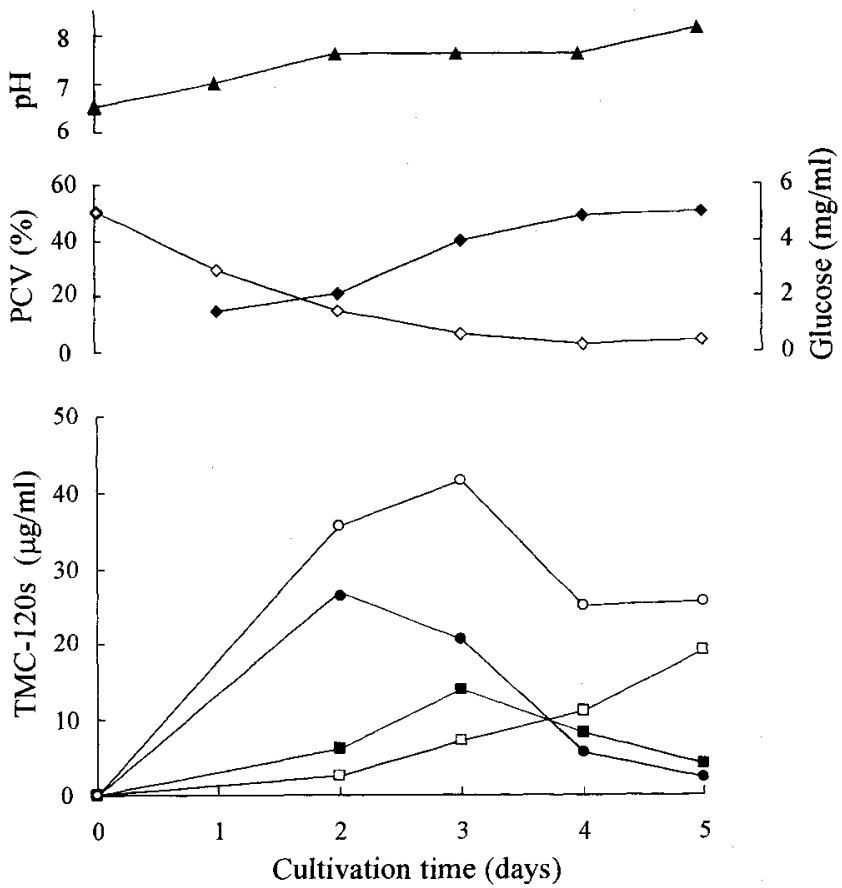

Fig. 3. Isolation and purification procedure for TMC-120A (1), B (2) and C (3).

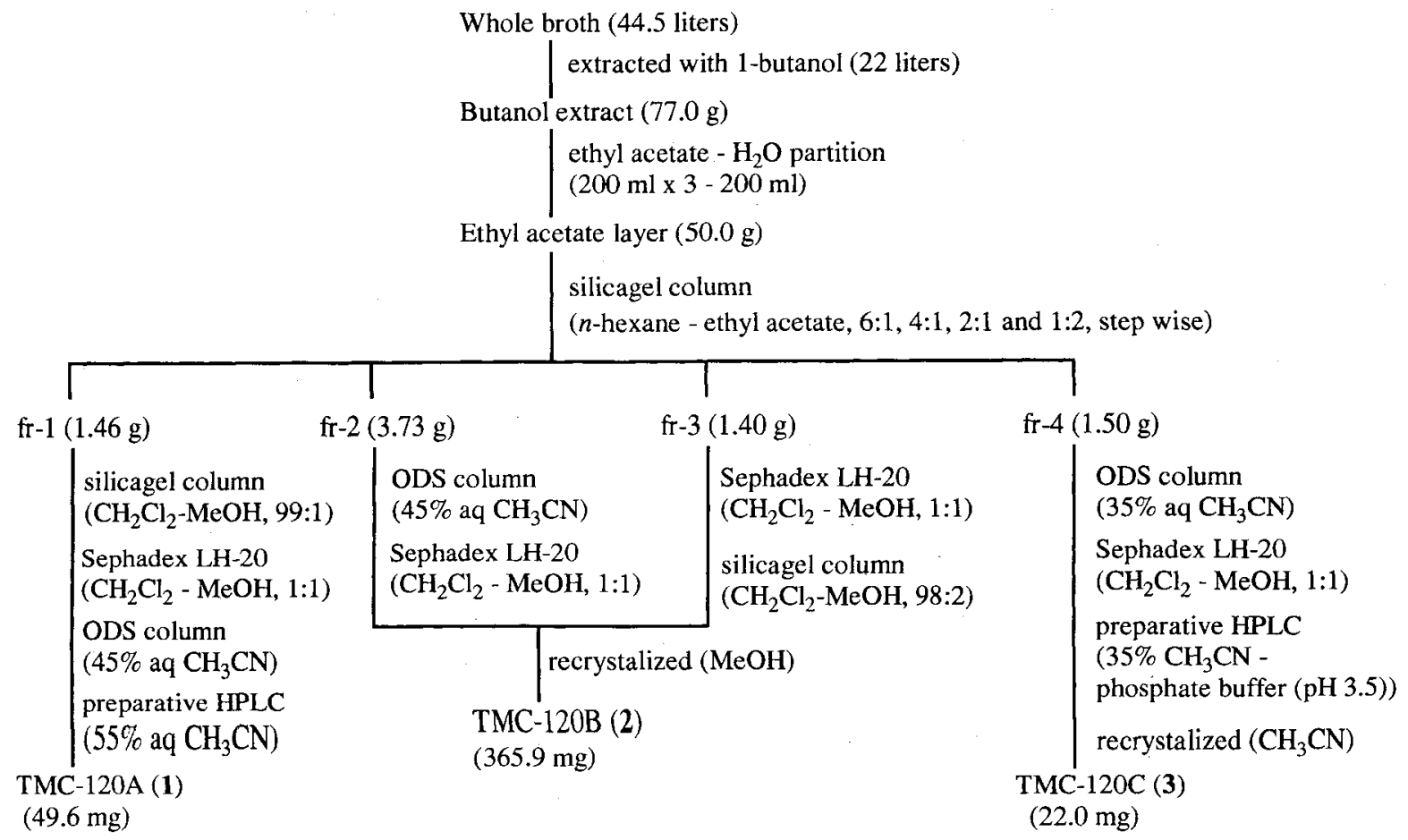


Fig. 4. The NOESY experiments of $\mathbf{4}$ and $\mathbf{5}$.

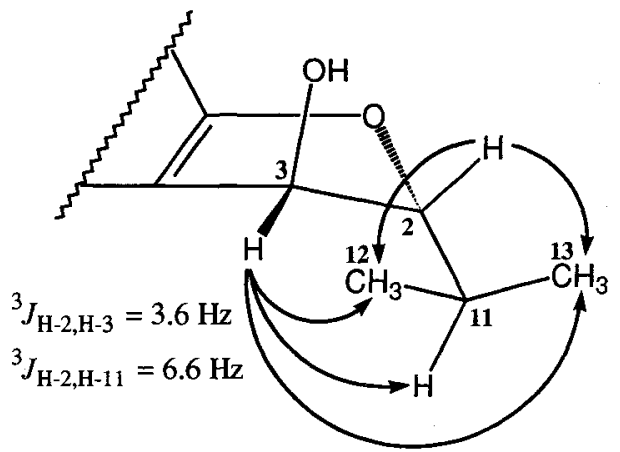

4 ( $E$ isomer)

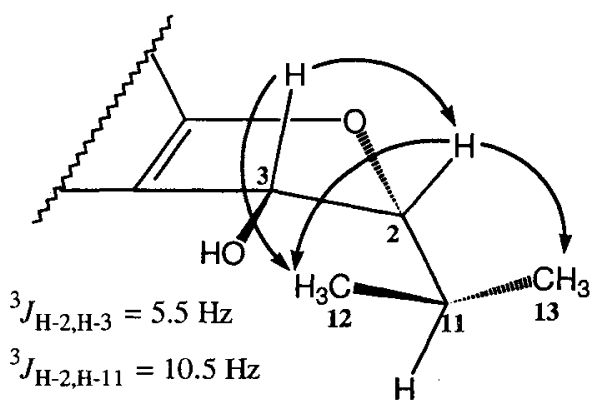

: NOE
Table 1. Inhibitory effects of $\mathbf{1} \sim \mathbf{5}$ on the survival of guinea pig peritoneal eosinophils.

\begin{tabular}{ccccc}
\hline \multicolumn{5}{c}{$\mathrm{IC}_{50}(\mu \mathrm{M})$} \\
\hline $\mathbf{1}$ & $\mathbf{2}$ & $\mathbf{3}$ & $\mathbf{4}$ & $\mathbf{5}$ \\
\hline 13.7 & 2.0 & $>39$ & $>41$ & $>41$ \\
\hline
\end{tabular}

TMC-120B (2) showed moderate inhibitory activity against the IL-5 mediated prolongation of eosinophil survival $\left(\mathrm{IC}_{50}=2.0 \mu \mathrm{M}\right)$, but $1,3,4$ and 5 which are reductive analogs of 2 , were less active than 2 or inactive (Table 1). These results suggested that the $\alpha, \beta$-unsaturated ketone of 2 played an important role for the activity, involving the alkylation of biological nucleophiles in a MICHAEL-type addition. TMC-120B showed no cytotoxicity against human leukemia HL-60 at the concentration of 42 $\mu \mathrm{M}$.

\section{Experimental}

\section{Microorganism}

The producing fungal strain TC 1118 was isolated from rhizosphere of grass collected in Kawaguchi-shi, Saitama, Japan. It was identified as Aspergillus ustus (Bain.) Thom \& Church on the basis of the following distinct characteristics; dull gray conidial area, yellow reverse side of colonies, small vesicles of $6 \sim 18 \mu \mathrm{m}$ in diameter, long brownish stipes, and globose to subglobose, rough-walled conidia of $4.0 \sim 5.5 \times 2.5 \sim 3.0 \mu \mathrm{m}$ from biseriate aspergilla.

\section{Fermentation}

Seed and production medium contained glucose $0.5 \%$, glycerol $2.0 \%$, soybean meal $2.0 \%$, yeast extract $0.2 \%$, $\mathrm{CaCO}_{3} 0.4 \%$ and $\mathrm{NaCl} 0.25 \%$ ( $\mathrm{pH}$ 6.5). Growth of the organism was evaluated as packed cell volume (PCV) by centrifuging the fermentation broth. The PCV was recorded as $\%$ of total broth volume. The production of TMC- $120 \mathrm{~s}$ during the fermentation, was analyzed by HPLC of the 1 butanol extract of the fermentation broth.

\section{HPLC Analysis}

Analytical HPLC was carried out on a Hewlett-Packard HP-1090 equipped with a diode array detector. The conditions for HPLC analysis were as follows; column: YMC-Pack ODS-AM AM-301-3 (4.6×100 mm), mobile phase: $55 \%$ aq $\mathrm{CH}_{3} \mathrm{CN}$, flow rate: $1.2 \mathrm{ml} /$ minute, detection: UV at $254 \mathrm{~nm}$. Under these conditions, TMC-120A, B and C eluted at $3.9,4.2$ and 2.1 minutes, respectively.

\section{Reduction of 2 with Sodium Borohydride}

To a solution of $2(39.1 \mathrm{mg}, 0.164 \mathrm{mmol})$ in ethanol (20 $\mathrm{ml}$ ), sodium borohydride $(7.8 \mathrm{mg}, 0.206 \mathrm{mmol})$ was added. After stirring at room temperature for 5 hours, the reaction mixture was neutralized by addition of $1 \mathrm{~N} \mathrm{HCl}$. The resulting mixture was concentrated and purified by 
preparative HPLC ( $50 \%$ aqueous $\left.\mathrm{CH}_{3} \mathrm{CN}\right)$ to separate 4 and 5 , which were further purified by a Sephadex LH-20 column $(22 \times 440 \mathrm{~mm})$ with $\mathrm{CH}_{2} \mathrm{Cl}_{2} / \mathrm{MeOH}(1: 1)$ to yield 4 (7.6 $\mathrm{mg}, 19.1 \%$ ) and $\mathbf{5}(16.1 \mathrm{mg}, 40.4 \%)$, respectively.

4: Pale yellow solid; UV $\lambda_{\max }(\log \varepsilon): 344(3.72), 305$ (3.50), 293 (sh, 3.46$), 241$ (4.22), 225 (4.38), 210 (4.49) nm; IR $v_{\max }: 3350 \sim 3200,2955,2920,2870,1640,1570$, $1460,1425,1385,1375,1355,1270,1160,1080,985$ $\mathrm{cm}^{-1}$; ESI-MS (positive) $m / z \quad 244(\mathrm{M}+\mathrm{H})^{+}, 226$ $\left(\mathrm{M}+\mathrm{H}-\mathrm{H}_{2} \mathrm{O}\right)^{+}, 210,188,173$; ESI-MS (negative) $m / z 242$ $(\mathrm{M}-\mathrm{H})^{-}$; HRESI-MS $m / z$ found $242.1147(\mathrm{M}-\mathrm{H})^{-}$, calcd. for $\mathrm{C}_{15} \mathrm{H}_{16} \mathrm{NO}_{2}: 242.1181 ;{ }^{1} \mathrm{H}$ NMR in $\mathrm{CDCl}_{3}: \delta(\mathrm{ppm})$; 9.28 (s, H-9); 7.60 (d, 8.5 Hz, H-4); 7.39 (s, H-6); 7.21 (d, $8.5 \mathrm{~Hz}, \mathrm{H}-5) ; 5.26$ (d, $3.6 \mathrm{~Hz}, \mathrm{H}-3) ; 4.52$ (dd, $6.6 \mathrm{~Hz}, 3.6 \mathrm{~Hz}$, $\mathrm{H}-2) ; 2.65$ (s, H-10); 2.03 (m, H-11); 1.07 and 1.06 (d, 6.7 $\mathrm{Hz}, \mathrm{H}-13$ and 12$) ;{ }^{13} \mathrm{C} \mathrm{NMR}$ in $\mathrm{CDCl}_{3}: \delta(\mathrm{ppm}) ; 157.0(\mathrm{~s}$, C-9b); 152.5 (s, C-7); 146.8 (d, C-9); 138.5 (s, C-5a); 127.4 (d, C-4); 122.4 (s, C-3a); 118.6 (d, C-6); 118.3 (d, C-5); 114.5 (s, C-9a); 97.9 (d, C-2); 75.5 (d, C-3); 31.5 (d, C-11); 24.2 (q, C-10); 17.7 and 17.6 (q, C-13 and 12).

5: Pale yellow solid; UV $\lambda_{\max }(\log \varepsilon): 343$ (3.79), 305 (3.53), 293 (sh, 3.48), 241 (4.29), 225 (4.47), 210 (4.57) $\mathrm{nm}$; IR $v_{\max }: 3200,2950,2870,1640,1570,1425,1385$, $1350,1280,1265,1255,1170,1160,1125,1085,1065$, $1000,940 \mathrm{~cm}^{-1}$; ESI-MS (positive) $\mathrm{m} / \mathrm{z} 244(\mathrm{M}+\mathrm{H})^{+}, 226$ $\left(\mathrm{M}+\mathrm{H}-\mathrm{H}_{2} \mathrm{O}\right)^{+}, 210,188,173$; ESI-MS (negative) $\mathrm{m} / \mathrm{z} 242$ $(\mathrm{M}-\mathrm{H})^{-}$; HRESI-MS $m / z$ found $242.1155(\mathrm{M}-\mathrm{H})^{-}$, calcd. for $\mathrm{C}_{15} \mathrm{H}_{16} \mathrm{NO}_{2}: 242.1181 ;{ }^{1} \mathrm{H}$ NMR in $\mathrm{CDCl}_{3}: \delta$ (ppm); 9.19 (s, H-9); 7.66 (d, 8.3 Hz, H-4); 7.20 (s, H-6); 7.07 (d, $8.3 \mathrm{~Hz}, \mathrm{H}-5) ; 5.22$ (d, $5.5 \mathrm{~Hz}, \mathrm{H}-3) ; 4.20$ (dd, $10.5 \mathrm{~Hz}, 5.5$ $\mathrm{Hz}, \mathrm{H}-2) ; 2.54$ (s, H-10); 2.54 (m, H-11); 1.40 and 1.24 (d, $6.6 \mathrm{~Hz}, \mathrm{H}-13$ and 12$) ;{ }^{13} \mathrm{C} \mathrm{NMR}$ in $\mathrm{CDCl}_{3}: \delta(\mathrm{ppm}) ; 157.0$ (s, C-9b); 151.0 (s, C-7); 145.9 (d, C-9); 138.2 (s, C-5a); 128.5 (d, C-4); 124.3 (s, C-3a); 118.8 (d, C-6); 118.0 (d, C5); 114.1 (s, C-9a); 95.0 (d, C-2); 72.1 (d, C-3); 27.6 (d, C$11) ; 23.3$ (q, C-10); 19.9 and 19.5 (q, C-13 and 12).

Measurement of Eosinophil Survival

Eosinophils were obtained from peritoneal lavage fluid of guinea pigs sensitized with polymixin B. The cells were purified by centrifuge on a discontinuous Percoll density gradient. The purified eosinophils ( $>90 \%$ purity, $7.5 \times 10^{3} /$ well) were suspended in $100 \mu \mathrm{l}$ of RPMI-1640 medium containing $5 \%(\mathrm{v} / \mathrm{v})$ fetal calf serum, recombinant IL-5 $(0.1 \mathrm{ng} / \mathrm{ml})$ and various concentrations of drugs, and incubated at $37^{\circ} \mathrm{C}$ for 5 days in a humidified atmosphere containing $5 \% \mathrm{CO}_{2}$. The drugs were dissolved in DMSO and added to the medium. The final concentration of DMSO was adjusted to $0.1 \%(\mathrm{v} / \mathrm{v})$. The control medium contained the same amount of DMSO. After incubation, the cells were washed with PBS and the viability of the cells were determined by their ability to take up fluorescein diacetate.

\section{References}

1) GLEICH, G. J.: The eosinophil and bronchiral asthma: Current understanding. J. Allergy Clin. Immunol. 85: 422 436, 1990

2) Weller, P. F.: The immunobiology of eosinophils. N. Engl. J. Med. 324: 1110 1118, 1991

3) Her, E.; J. Frazer, K. F. Austen \& W. F. Owen, Jr.: Eosinophil hematopoietins antagonize the programmed cell death of eosinophils. Cytokine and glucocorticoid effects on eosinophils maintained by endothelial cellconditioned medium. J. Clin. Invest. 88: 1982 1987, 199.1

4) Rothenberg, M. E.; W. F. Owen, Jr., D. S. Silberstein, J. Woods, R. J. Soberman, K. F. Austen \& R. L. STEVENS: Human eosinophils have prolonged survival, enhanced functional properties, and become hypodense when exposed to human interleukin 3. J. Clin. Invest. 81: 1986 1992, 1988

5) Yamaguchi, Y; T. Suda, S. Ohta, K. Tominaga, Y. Miura \& T. KasAhara: Analysis of the survival of mature human eosinophils: interleukin-5 prevents apoptosis in mature human eosinophils. Blood 78: 2542 2547, 1991

6) Kohno, J.; H. Hiramatsu, M. Nishio, M. Sakurai, T. OKUDA \& S. Komatsubara: Structures of TMC-120A, B and $\mathrm{C}$, novel isoquinoline alkaloids from Aspergillus ustus TC 1118. Tetrahedron 55: 11247 11252, 1999 